\title{
ESTRATÉGIAS DE ECO-DESIGN E DE SUSTENTABILIDADE NA ÁREA DA CERÂMICA ESTRUTURAL EM PORTUGAL
}

\author{
LILIANA GOUVEIA | ESAD.CR/IPL - PORTUGAL \\ LIA GOMES |ESAD.CR/IPL - PORTUGAL \\ JOSÉ MANUEL C. B. C. FRADE, Dr. | ESAD.CR/IPL - PORTUGAL
}

\begin{abstract}
RESUMO
Estratégias de eco-design e de sustentabilidade têm sido usadas para diferenciar os produtos cerâmicos em geral e os cerâmicos estruturais em particular. No presente artigo pretendem-se apresentar os resultados relativos á investigação que foi realizada no projeto CP2S - Cerâmica, Património e Produto Sustentável, do ensino à indústria, nomeadamente no seu eixo de investigação relacionado com a identificação das principais estratégias de eco-design e de sustentabilidade aplicadas por este setor tendo em vista diferenciar, criar valor e introduzir inovação na cerâmica estrutural.
\end{abstract}

\section{INTRODUÇÃO}

Este artigo pretende apresentar e discutir alguns dos resultados do projeto de investigação cerâmica, património e produto sustentável - do ensino à indústria (CP2S) que tem lugar no Laboratório de Investigação em Design e Artes (LIDA) da Escola Superior de Artes e Design de Caldas da Rainha (ESAD.CR) do Instituto Politécnico de Leiria (IPLeiria), Portugal, nomeadamente no que diz respeito à investigação das principais estratégias de sustentabilidade que as empresas industriais de cerâmica do subsetor estrutural aplicam ao nível do design, da produção e da comercialização tendo em vista conseguir introduzir nos mercados nacionais e internacionais produtos com cariz sustentável cuja diferenciação contrubui para a valorização destes produtos sustentáveis relativamente a outros produtos concorrentes. A cerâmica industrial tradicional subdivide-se em quatro principais subsetores: utilitário e decorativo; pavimentos e revestimentos; sanitários e estruturais, sendo estes últimos o objeto do presente artigo, onde se apresentam alguns exemplos de estudo. Noutros artigos poderão serão apresentados mais exemplos deste subsetor e dos outros subsetores cerâmicos.

\section{DISCUSSÃO E RESULTADOS GERAIS}

Neste trabalho fizeram-se visitas as várias empresas industriais do subsetor da cerâmica industrial e estudaram-se os respetivos produtos no sentido de selecionar os produtos sustentáveis que neste caso foram cerca de 100. A maioria deste produtos são tijolos extrudidos ou prensados; coberturas de telhados ou telhas e respetivas peças de complemento; pavimenos e revestimentos de fachadas extrudidos. De seguida a título de exemplo apresenta-se algumas fotos desses produtos e discutem-se as estratégias de sustentabilidade que estiveram na sua origem.

A cerâmica estrutural privilegia o uso de matérias-primas muito abundantes (quase sempre argilas vermelhas) e altamente disponíveis, de baixo custo, compatíveis com ciclos de cozedura a mais baixas temperaturas, algumas vezes rápidos (figuras 1 a 8). A mistura destas argilas vermelhas com argilas que cozem branco, em diferentes quantidades relativas, produzem a baixo custo produtos com uma variação cromática que pode ser interessante do ponto de vista de design sustentável (figura 1). Estas condições promovem a fabricação de produtos de reduzido custo o que democratiza o seu acesso para variados fins, especialmente nas áreas da construção civil e da arquitetura.

As argilas vermelhas conferem quase sempre elevada plasticidade às pastas cerâmicas, propriedade adequada 
para a conformação de produtos com formas simples através de tecnologias de baixo custo como são a prensagem ou a extrusão.

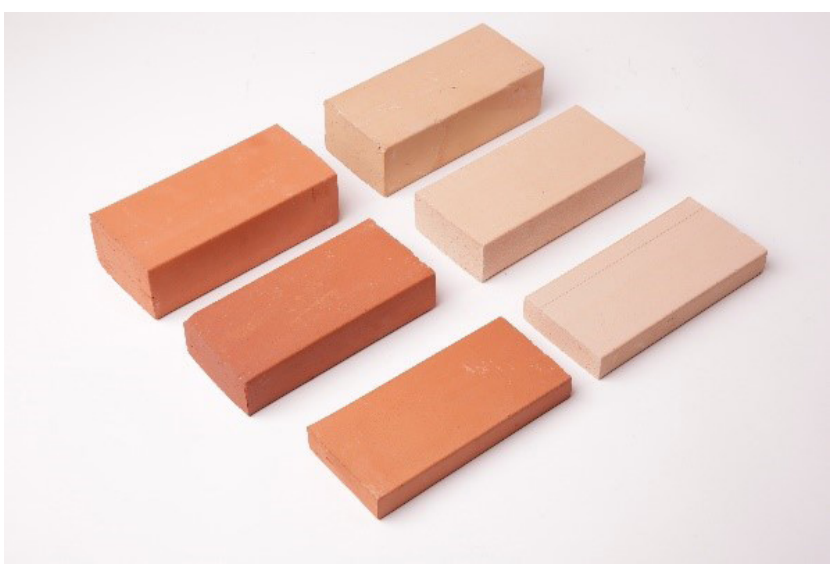

Foto 1: Tijolos prensados cuja cor resulta de diferentes combinações de argilas de diferentes tonalidades após cozedura (produto da fábrica Torreense).

Fonte: (Autor: Pedro Cá)

Nas figuras 2 e 3 apresenta-se o tijolo térmico produzido por extrusão e que apresenta um conjunto de qualidades que contribuem favoravelmente para o isolamento térmico ( e acústico) dos edifíos construídos com este matéria cozida de argila vermelha, estes produtos conformados por extrusão apresentam uma grande volume de espaços vazios que melhora o desempenho de isolamento térmico - com efeito sobre a redução do consumo energético na fase de uso - e de isolamento acústico. Outro dado interssante é que o design deste produto impõe um conjunto de guias macho/femea (figura 3) que para além de simplicifar o processo de aplicação (montagem), reduz a quantidade de argamassa necessária para colagem entre eles cuja condutividade térmica é comparativamente maior do que a do material cerâmico do próprio tijolo. Na figura 5, apresenta-se um tijolo extrudido que integra uma cavidade para moldação do betão armado, que simplifica o processo de construção e reduz (ou elimina) a quantidade de material necessário (madeiras, metais, etc) para fazer as cofrangens (moldes) dos processos construtivos.

Baseado no mesmo princípio de sustentabilidade que visa a simplificação dos processos construtivos, apresenta-se na figura 5 uma telha dupla que exige menos tempo de trabalho para a construção de uma cobertura ou teIhado relativamente à utilização de telhas convencionais. Acresce nesta situação uma redução do número de juntas

de ligação entre telhas e por isso o aumento do isolamento térmico do conjunto que está em linha com a redução de necessidades energéticas para o aquecimento ou arrefecimento de espaços interiores.

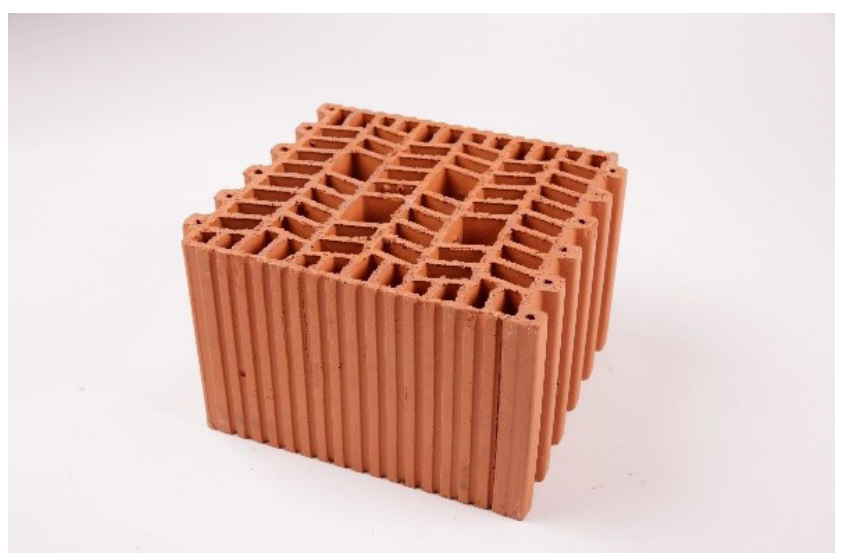

Foto 2: Tijolo (produto da fábrica Preceram) Fonte: (Autor: Pedro Cá)

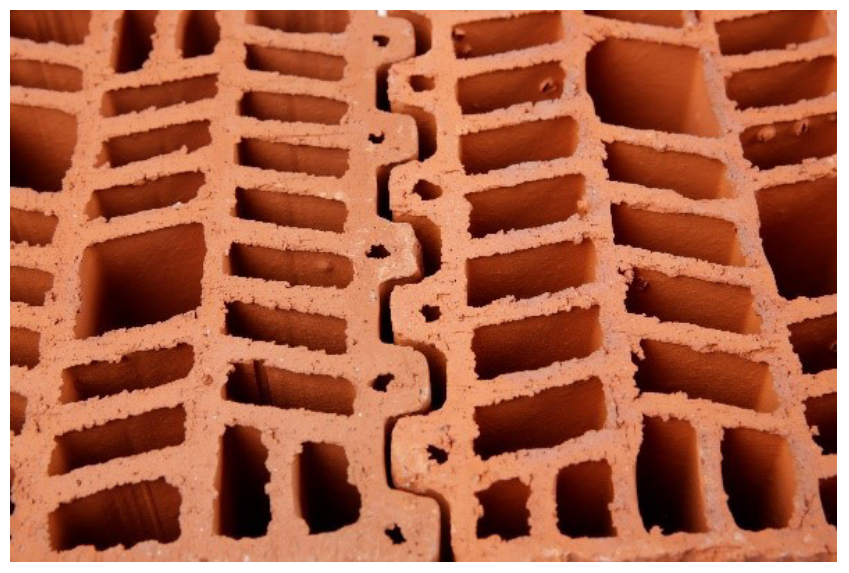

Foto 3: Pormenor do encaixe entre tijolos "térmicos" (produtos da fábrica Preceram). Fonte: (Autor: Pedro Cá)

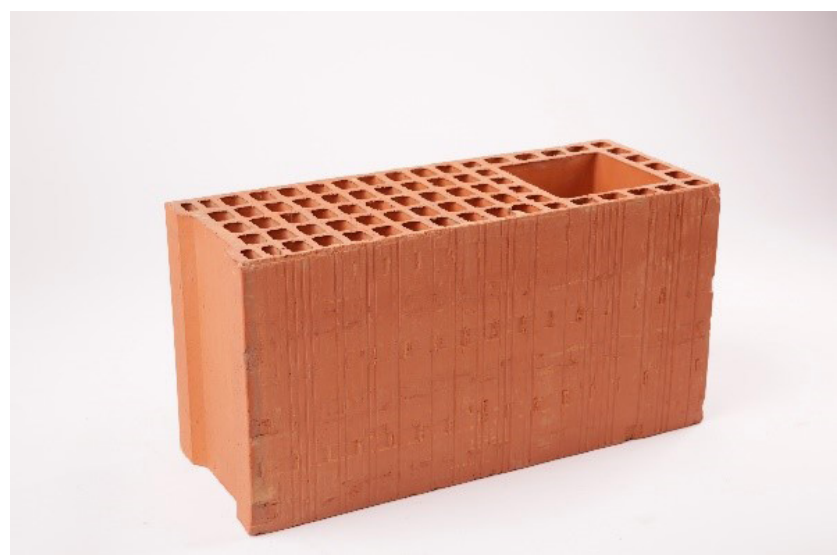

Figura 4: Tijolo extrudido com molde para betão armado (produtos da fábrica Prélis). Fonte: (Autor: Pedro Cá) 


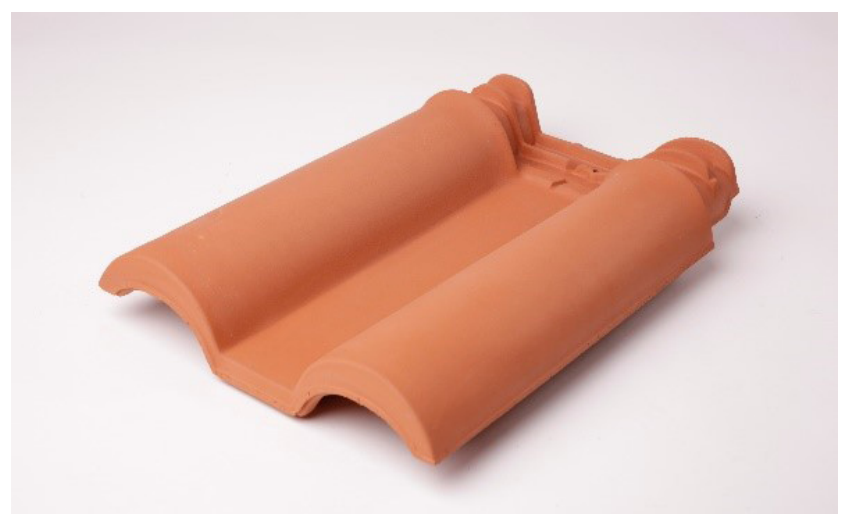

Figura 5 : Duplat-telha prensada (produto da fábrica CS Coelho da Silva). Fonte: (Autor: Pedro Cá)

Na figura 6, apresenta-se uma telha simples multifuncional que conjuga as características de cobertura e entrada de luz nos edifícios, fator importante para a sustentabilidade deste produto. A utilização de luz natural reduz o consumo energético que seria necessário para o mesmo fim.

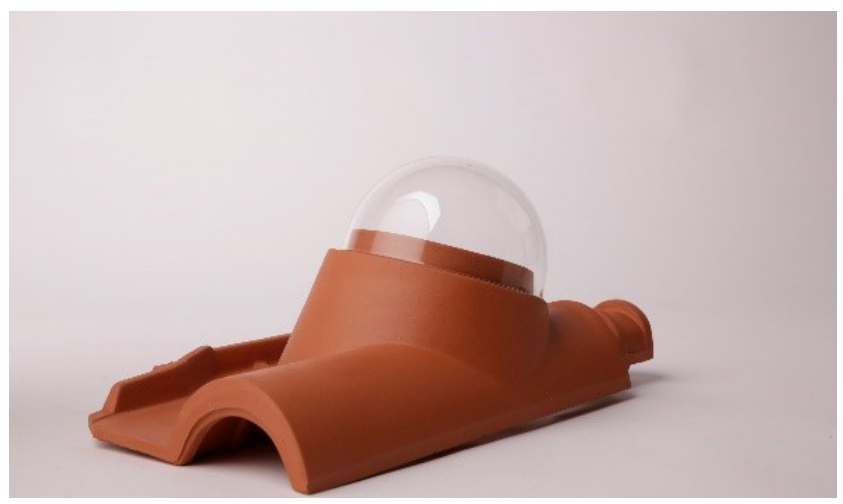

Figura 6: Telha prensada com claraboia transparaente para entrada de luz (produto da fábrica (S Coelho da Silva)

Fonte: (Autor: Pedro Cá)

Finalmente nas figuras 7 e 8 apresenta-se placas simples extrudidas em barro vermelho para montagem de fachadas ventiladas em edifícios. Estes produtos são montados nas paredes exteriores das edificações deixando entre estas placas e as paredes dos edifícios uma caixa de ar que faz o isolamento térmico. Na comparação entre as duas figuras verifica-se o potencial que a extrusão tem na diferenciação do design de produtos similares e na moldação de sistemas de encaixe rápido, simples e reversível entre placas, fatos extremamente importantes do ponto de vista da sustentabilidade dos produtos.

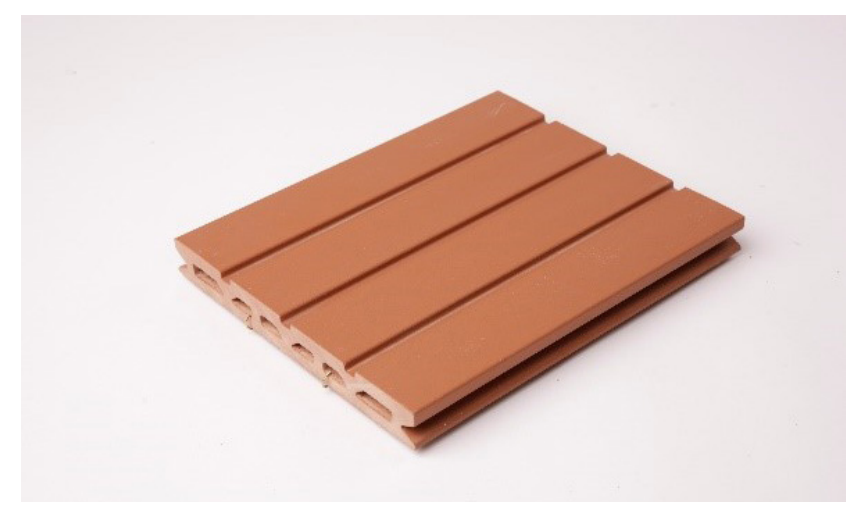

Figura 7: Placa extrudida para fachada ventilada (produto da fábrica Soladrilhos). Fonte: (Autor: Pedro Cá)

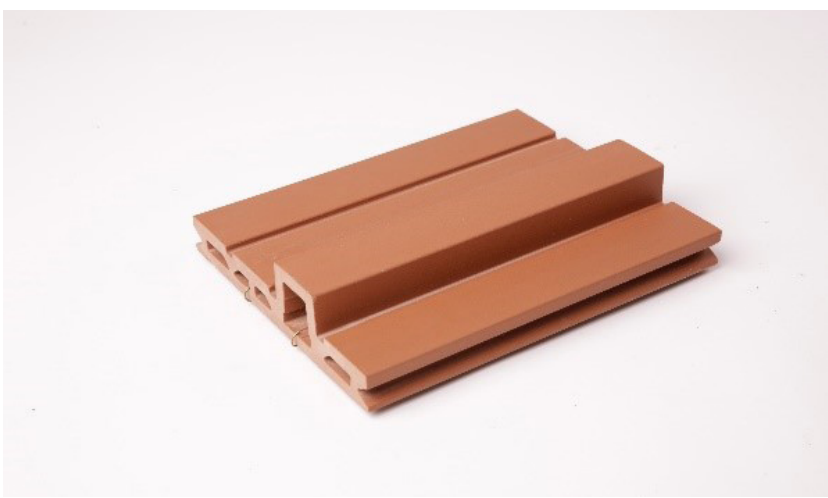

Figura 8: Placa extrudida para fachada ventilada (produto da fábrica Soladrilhos). Fonte: (Autor: Pedro Cá)

Finalmente é importante acrescentar que são conhecidos exemplos da introdução de resíduos próprios na pasta que é usada na conformação destes produtos estruturais, tal como são conhecidos exemplos da introdução de resíduos provenientes de outros setores industriais que são usados como combustíveis ou para aumentarem a resistência mecânica dos produtos finais, em especial dos tijolos, acontecimentos que abrem a oportunidade futura de discutir estes assuntos na perspetiva da economia circular e design circular.

\section{AGRADECIMENTOS}

O Projeto CP2S, "Cerâmica, Patrimônio e Produto Sustentável - do ensino à indústria", agradece o apoio FEDER - Fundo Europeu de Desenvolvimento Regional, no âmbito do Programa Portugal 2020 Programa Operacional Regional do Centro (CENTRO01-0145-FEDER-23517) e a todas as empresas que ofereceram produtos cerâmicos para constituir a coleção de produtos cerâmicos industriais sustentáveis. 